\title{
A search for conditioned reinforcement effects in negative automaintenance of keypecking
}

\author{
AARON J. BROWNSTEIN and PETER D. BALSAM \\ University of North Carolina at Greensboro, Greensboro, North Carolina 27412
}

\begin{abstract}
The relationship between pecking and keylight termination was systematically varied to assess possible conditioned reinforcement effects of keylight termination in negative automaintained pecking. Pecking was observed under conditions where pecking produced sustained keylight termination, brief keylight termination, or had no effect on key illumination. The proportion of trials with a peck was unrelated to the peck-termination contingency. The latency on trials with a peck was shortest in the sustained termination condition. The rate of pecking on trials with a peck was highest in the condition where termination was independent of pecking. Overall, the results provide little support for the notion that keylight termination functions as a conditioned reinforcer in the negative automaintenance paradigm.
\end{abstract}

Keypecking by pigeons may be established and maintained by pairing key illumination with grain presentation (Brown \& Jenkins, 1968). Williams and Williams (1969) have demonstrated that keypecking will be maintained by pairing even when a negative contingency is established between pecking and grain presentation (negative automaintenance). One procedure used to demonstrate negative automaintained pecking consisted of illuminating the key for several seconds at irregular intervals. If no pecking occurred, the keylight was terminated and grain presented. If pecking occurred, the keylight was immediately terminated and no grain presented.

Schwartz (1972) has investigated the possibility that keylight offset may become a conditioned reinforcer in the above procedure, and response contingent conditioned reinforcement (keylight offset) may be involved in the maintenance of keypecking. Schwartz modified the key illumination/grain relationship so that on trials where no peck occurred, the keylight terminated simultaneously with the end of the grain presentation period rather than with the start of the grain presentation period. Additionally, two groups were differentiated with respect to keylight consequences on trials where pecks occurred. In one group, pecks immediately terminated the keylight. In the second group, the keylight stayed on for a fixed period on trials regardless of whether pecks occurred. Keypecking was maintained at a high level in both groups. This outcome argues convincingly that response contingent conditioned reinforcement based on keylight termination is not a necessary factor in the type of maintained keypecking reported by Williams and Williams.

A report based on this research was presented at the meeting of the Southeastern Psychological Association, Hollywood, Florida, 1974. Reprints may be obtained from either author, Department of Psychology, University of North Carolina at Greensboro, Greensboro, North Carolina 27412.
The present experiment further examined the possibility that keylight termination functions as a conditioned reinforcer in the negative automaintenance procedure. Throughout the experiment, keylight termination preceded grain presentation on trials where pecks did not occur, i.e., the standard Williams and Williams procedure. Thus, keylight termination could become a conditioned reinforcer. To assess the possibility that keylight termination was functioning as a conditioned reinforcer, the relationship between pecking and keylight termination was systematically varied. In the first phase, the keylight remained on for a fixed period on each trial, i.e., keylight termination was independent of responding. During the second phase, each peck on the illuminated key turned the keylight off briefly. In the final phase, a peck on the illuminated key terminated the keylight, and the keylight was not turned on again until the next trial. If keylight termination was functioning as a conditioned reinforcer, differences among conditions in rate, probability, and latency of responding would be expected where these measures are appropriate for the experimental conditions.

\section{METHOD}

\section{Subjects}

Six adult White Carneaux pigeons were maintained at approximately $80 \%$ of their free-feeding weights. All subjects had been exposed to fixed trial negative automaintenance procedures for 30 days prior to the start of the present experiment.

\footnotetext{
Apparatus

The experimental enclosure was a modified two-key Lehigh Valley Electronics pigeon chamber. One key remained covered by a metal plate throughout the experiment. The second key was transilluminated by two GE No. 1820 light bulbs. These bulbs were in series with $63 \mathrm{ohms}$ resistance. General illumination was provided by two additional GE No. 1820 bulbs located in the upper right corner of the intelligence panel. The general illumination was present at all times except during feeder operation.
} 
Table 1

Proportion of Trials With a Peck

\begin{tabular}{|c|c|c|c|c|c|c|}
\hline \multirow[b]{2}{*}{ Subjects } & \multicolumn{2}{|c|}{ Fixed Trials Condition } & \multicolumn{2}{|c|}{ Brief Termination Condition } & \multicolumn{2}{|c|}{ Standard Condition } \\
\hline & 5-Day Mean & 5-Day Range & 5-Day Mean & 5-Day Range & 5-Day Mean & 5-Day Range \\
\hline A9 & .795 & $.700-.900$ & .840 & $.775-.900$ & .535 & $.100-.725$ \\
\hline A 10 & .290 & .150-.450 & .025 & $.000-.075$ & .025 & $.000-.075$ \\
\hline A11 & .055 & $.000-.100$ & .025 & $.000-.075$ & .010 & $.000-.025$ \\
\hline A12 & .645 & $.525-.725$ & .620 & $.350-.800$ & .890 & $.575-.975$ \\
\hline B1 & .910 & $.875-.975$ & .915 & $.850-.950$ & .940 & $.750-1.000$ \\
\hline B2 & .620 & $.475-.800$ & .635 & $.550-.750$ & .825 & $.675-.925$ \\
\hline Group & .553 & & .510 & & .530 & \\
\hline
\end{tabular}

\section{Procedure}

Subjects were given daily sessions composed of $\mathbf{4 0}$ trials. Trials occurred aperiodically with a mean intertrial interval of $30 \mathrm{sec}$. A trial consisted of a period of keylight illumination. Following trials in which no peck occurred, subjects were given access to grain for a fixed number of seconds (range 2-8 sec over subjects). Keypecks during a trial resulted in the omission of the grain presentation for that trial. This negative contingency was in effect throughout the experiment. The experimental conditions manipulated the relationship between pecking and keylight termination. In the first condition, a fixed-trials procedure was in effect. The keylight was on for $8 \mathrm{sec}$ on each trial. Keylight termination was independent of responding. In the second condition, each trial lasted $8 \mathrm{sec}$; however, each peck during the trial briefly terminated ( 45 millisec) the keylight. In the final condition, a peck terminated the keylight for the remainder of the trial. Each condition was in effect for 10 days.

\section{RESULTS}

Negative automaintained keypecking was reliably obtained in all subjects. At the start of the present experiment, which was approximately 30 days since the subjects were first introduced to the fixed trials procedure, five of the six birds were still pecking on a substantial proportion of trials. Table 1 shows mean proportion of trials with a peck for the last 5 days of the three phases of the experiment. During Phase II, each peck produced a brief termination of the keylight. Comparison of the performance shown in Table 1 for Phases I and II indicates no very consistent nor statistically reliable effect across birds. Response-produced brief termination of the keylight does not seem to effect the proportion of trials with a peck. During Phase III, each peck terminated the keylight for the remainder of the trial. Compared to previous phases, three of the birds show large changes in mean performance. Two birds show an increase, and one bird shows a decrease. For all birds, however, there is still considerable overlap in the distribution of daily proportions for the data presented in Table 1. Response produced keylight termination does not seem to produce a consistent change in performance as indicated by proportion of trials on which a peck occurred.

Response contingent light termination was used in Phases II and III to examine the possibility that keylight termination functions as a conditioned reinforcer. If conditioned reinforcement was involved, an increase in the proportion of trials with a peck should occur. However, if this increase in pecking had occurred, it would have produced a decrease in the number of keylight-grain pairings. It is possible that these factors are offsetting, and the terminal performances show no change. However, examination of proportion of pecks on earlier days in Phases II and III, where conditioned reinforcement effects might be expected to be manifested prior to the possibility of being offset by other factors, reveals no significant changes from the data presented in Table 1.

During Phase I and Phase II, where trial length was fixed, a meaningful rate measure could be obtained. Table 2 shows the mean rate of responding on trials with a peck over the last 5 days of each condition. Five of the six subjects show a reduction in response rate in the brief termination condition. This reduction was statistically significant $(A=.2879$, Sandler, 1955). This outcome is contrary to what would be expected if the brief flash was functioning as a conditioned reinforcer.

Table 3 presents the mean latency on trials with a peck over the last 5 days of each condition. For five of the six subjects, the average latency is shorter in the standard condition than it is in either of the other conditions. The differences among the conditions was statistically significant $(\mathrm{F}=3.98, \mathrm{df}=2 / 10)$.

Summarizing the results with respect to the three measures: (1) the proportion of trials with a response was not reliably affected by manipulating the relationship between responding and keylight termination; (2) rate of responding was reliably reduced

Table 2

Responses Per Minute on Trials With a Peck

\begin{tabular}{|c|c|c|c|c|}
\hline \multirow[b]{3}{*}{ Subjects } & \multicolumn{4}{|c|}{ Condition } \\
\hline & \multicolumn{2}{|c|}{ Fixed Trials } & \multicolumn{2}{|c|}{ Brief Termination } \\
\hline & $\begin{array}{l}\text { 5-Day } \\
\text { Mean }\end{array}$ & $\begin{array}{l}\text { 5-Day } \\
\text { Range }\end{array}$ & $\begin{array}{l}\text { 5-Day } \\
\text { Mean }\end{array}$ & $\begin{array}{l}\text { 5-Day } \\
\text { Range }\end{array}$ \\
\hline A9 & 17.8 & $12.6-24.6$ & 17.8 & $12.9-23.4$ \\
\hline A10 & 8.9 & $7.5-10.5$ & 7.5 & $7.5-8.5$ \\
\hline A11 & 9.0 & $7.5-11.3$ & 8.3 & $7.5-10.5$ \\
\hline A12 & 16.4 & $11.9-20.9$ & 9.9 & $8.0-11.9$ \\
\hline B1 & 22.1 & $20.0-28.4$ & 19.3 & $16.4-22.7$ \\
\hline B2 & 16.5 & $11.4-24.1$ & 12.0 & $10.8-13.2$ \\
\hline Group & 15.1 & & 12.5 & \\
\hline
\end{tabular}


Table 3

Latency (Seconds) of the First Response on Trials With a Peck

\begin{tabular}{|c|c|c|c|c|c|c|}
\hline \multirow[b]{2}{*}{ Subjects } & \multicolumn{2}{|c|}{ Fixed Trials Condition } & \multicolumn{2}{|c|}{ Brief Termination Condition } & \multicolumn{2}{|c|}{ Standard Condition } \\
\hline & 5-Day Mean & 5-Day Range & 5-Day Mean & 5-Day Range & 5-Day Mean & 5-Day Range \\
\hline A9 & 4.14 & $3.54-4.50$ & 4.56 & $3.84-5.34$ & 3.06 & $2.10-3.78$ \\
\hline A10 & 4.26 & $2.76-5.28$ & 3.72 & $1.50-6.06$ & 4.02 & $2.70-4.92$ \\
\hline A11 & 2.76 & $1.50-5.10$ & 6.42 & $5.52-7.09$ & 2.28 & $.90-3.30$ \\
\hline A12 & 6.12 & $5.64-6.54$ & 5.76 & $5.22-6.06$ & 1.86 & $1.68-2.10$ \\
\hline B1 & 3.66 & $3.06-4.56$ & 3.90 & $3.66-4.14$ & 3.42 & $2.46-4.26$ \\
\hline B2 & 4.80 & $3.66-5.34$ & 4.44 & $4.20-4.86$ & 3.12 & $2.34-3.66$ \\
\hline Group & 4.32 & & 4.80 & & 2.94 & \\
\hline
\end{tabular}

when a brief keylight termination was produced by each response; (3) the standard automaintenance procedure resulted in shorter response latencies.

\section{DISCUSSION}

The most frequently encountered dependent measure in studies of automaintenance is proportion of trials with a response. In studies designed to assess possible conditioned reinforcement effects, the primary and usually sole concern has been with this measure. The present study provides no support for the view that keylight termination was functioning as a conditioned reinforcer when assessed by this measure. Neither response contingent brief nor sustained keylight termination increased the proportion of trials with a peck over that obtained when keylight termination was not response contingent.

The decrease in response rate when brief keylight termination was made contingent on pecking is contrary to what would be expected if keylight termination functioned as a conditioned reinforcer. Reinforcing effects of brief stimuli paired with grain have been demonstrated in other contexts where response contingent brief stimuli support rate increases (Stubbs, 1971). The present results suggest, however, that within the context of the negative automaintenance paradigm, brief stimulus effects are not easily demonstrated. The failure to demonstrate conditioned reinforcement effects on response rate with the briefly terminated stimulus may result from additional incompatible functions of the briefly terminated stimulus in the negative automaintenance paradigm. To the extent that keypecks result from stimulus-grain contingencies, the brief termination procedure should have a suppressive effect on pecking after the first peck on any trial. This follows from the fact that the first peck changes the stimulus to one not paired with food. In other words, grain never follows a trial where the keylight has been briefly terminated.

It is not easy to discern whether the decrease in rate observed is the net result of conditioned reinforcement and other factors involved in the brief termination procedure or a simple effect of this latter class of factors. Neither possibility ascribes a very strong role to conditioned reinforcement, as is consistent with the observed rate decrease in the brief termination condition.

A more positive demonstration of conditioned reinforcement effects appears to be provided by the differences in latency found among experimental conditions. Response contingent sustained keylight termination reduced the latency of the first response. This reduction in latency cannot be unequivocally regarded as a consequence of conditioned reinforcement effects of keylight termination. First, the effect was not found during the brief termination condition. Second, and more significant, in the condition in which the effect was found, trial duration is in part under the control of the subject. The average trial duration (keylight on) is slightly more than $5 \mathrm{sec}$ in the third condition as contrasted with $8 \mathrm{sec}$ in the other conditions of the experiment.
Groves (1974) has demonstrated that negatively automaintained keypecking is inversely related to the ratio of trial size to interreinforcement interval. Thus, the control of a significant variable rests in the subject's behavior and may be responsible for the latency reduction. The decreased latency may reflect an equilibrium point between positive response tendencies generated by average shorter trial durations resulting from trials with a peck (Groves, 1974) and negative response tendencies resulting from decreased association of keylight and grain resulting from trials with a peck (Gonzales, 1974; Schwartz \& Williams, 1972). Indirect support for this view may be obtained from the relative latencies. During the first and second conditions, the mean latencies are equal to $54 \%$ and $60 \%$ of the trial duration. During the third condition, the relative latency dropped to $36 \%$ if the scheduled 8 -sec trial duration is used in the determination. However, if the obtained average trial duration $(5.22 \mathrm{sec})$ is used, this value is $56 \%$.

Several studies have demonstrated that if keypecks delay keylight termination as well as cancel grain presentation, pecking will decline (Hursh, Navarick, \& Fantino, 1974; Hitzing, Note 1). This outcome has been interpeted as the result of delaying conditioned reinforcement from keylight termination. However, such an effect would be expected from the increase in the ratio of trial size to interreinforcement interval produced by this procedure and thus cannot be regarded as an unequivocal conditioned reinforcement effect.

An additional difficulty in emphasizing conditioned reinforcement as a primary factor in negative automaintenance concerns the stronger effects of alleged conditioned reinforcers as contrasted with primary reinforcers. The keypeck produces keylight termination but cancels grain. One interesting suggestion (Hursh, Navarick, \& Fantino, 1974) notes that in the standard trial terminating procedure, immediacy of the two sources of reinforcement is not equal, and the bird's behavior may be more consistent with the control by the immediate conditioned reinforcement rather than the delayed primary reinforcement. Such a difference in immediacy is not present in the fixed trial procedure of the present study, or in the study reported by Schwartz (1972). Keypecking was readily maintained in both studies, however. Additionally, Williams and Williams (1969, Experiment III) demonstrated that pigeons peck more on a key which provided only delayed primary reinforcement (fixed trial response independent food procedure) than on a simultaneously available key that provided immediate conditioned reinforcement but cancelled food presentations (standard automaintenance procedure). Thus, the behavior of these birds was not under the control of the immediately available conditioned reinforcement to the extent that might be expected on the basis of the Hursh et al. hypothesis.

In summary, our search for conditioned reinforcement effects has not been very fruitful. Unqualified demonstrations of appropriate effects were not readily obtained. Some seemingly conditioned reinforcement-inappropriate effects did appear. Moreover, the procedures commonly used to manipulate 
supposedly conditioned reinforcing events make it difficult to easily discern possible conditioned reinforcement effects in the negative automaintenance paradigm.

\section{REFERENCE NOTE}

1. Hitzing, E. W. Automaintenance: An analysis of the contingent nonreinforcement control procedure. Paper presented at Southeastern Psy chological Association, Atlanta, 1972.

\section{REFERENCES}

Brown, P., \& Jenkins, H. M. Autoshaping of the pigeon's keypeck. Journal of the Experimental Analysis of Behavior, 1968, 11, 1-8.

Gonzales, F. A. F. A. Effects of varying the percentage of key illuminations paired with food in a positive automaintenance procedure. Journal of the Experimental Analysis of Behavior, $1974,22,483-489$.

Groves, L. C. The effects of trial and cycle durations on automaintenance in the pigeon. Unpublished doctoral dissertation, University of North Carolina at Greensboro, 1974.
Hursh, S. R., Navarick, D. J., \& Fantino, E. “Automaintenance' : The role of reinforcement. Journal of the Experimental Analysis of Beh avior, 1974, 21, 117-124.

Sandler, J. A test of the significance of the difference between the means of correlated measures, based on a simplification of Students' t. British Journal of Psychology, 1955, 46, 225-226.

Schwartz, B. The role of positive conditioned reinforcement in the maintenance of keypecking which prevents delivery of primary reinforcement. Psychonomic Science, 1972, 28, primary $277-278$.

Stubbs, D. A. Second order schedules and the problem of conditioned reinforcement. Joumal of the Experimental Analysis of Behavior, 1971, 16, 289-313.

Williams, D. R. \& Williams, H. Automaintenance in the pigeon: Sustained pecking despite contingent nonreinforcement. Journal of the Experimental Analysis of Behavior, 1969, 12, 511-520.

(Received for publication April 28, 1975.) 